\title{
NEGOTIATING INTERPERSONAL AND MEDICAL TALK: FRAME SHIFTS IN THE GYNAECOLOGIC EXAM
}

\author{
Christina S. Beck \\ Department of Communication, Wilkes University, \\ Wilkes-Barre, PA 18766, USA \\ and \\ Sandra L. Ragan \\ Department of Communication, University of Oklahoma, \\ Norman, OK 73019, USA
}

\begin{abstract}
Extending from previous research on code switching and conversational framing, the present study focuses on the interaction between a nurse practitioner and her patients during gynaecologic exams. Specifically, this research found that the nurse practitioner and her patients initiated and responded to cues that shifted the medical encounter from medical to personoriented and then back to medical frames. Further, this research indicates that such frame shifts serve a rhetorical function in the encounter which facilitates the actual medical examination. Finally, these interactions exemplify the efficient and empathic integration of both interpersonal and medical dimensions of the medical examination.
\end{abstract}

\section{Introduction: Excerpt One}

1 NP: Well (.) lets get started here (.) hasn't rained yet has= $=$ it $^{\wedge}$

3 P: Not today (.) I don't know

4 NP: Probably'll wait til Saturday and then rain for graduation

5 P: Yah

$6 \quad($.

7 NP: Go ahead and scoot a:ll the way down here (.) a little $=$

$8=$ bit more (.) do you do your own breast exams

In the above excerpt from a gynaecologic exam, the nurse practitioner and her patient collaborate to fulfil the paramount medical agenda of the gynaecologic exam - the physical exam itself. However, the subtle shifts from medical (i.e. 
strict attention to medical tasks) to person-oriented (i.e. attention to patients' concerns and comfort) and back to medical frames which frequently recur throughout this nurse practitioner's interactions with her patients demonstrates an effective and efficient patient-centered approach to medical care. More importantly, this approach encourages the patient to be an active participant in her own health care rather than a passive recipient. As health communication researchers continue to advocate a holistic approach to medical encounters, the present research provides an initial response to how practitioners and patients may efficiently attend to both medical tasks and patient concerns through jointly produced activity.

After establishing the empirical and theoretical foundations for this study, exemplars of this nurse practitioner's and her patients' interactions will be examined in micro-detail. The conversation analytic method is used to explicate the achievement of recurrent medical and person-oriented 'frame-switching' by patient and nurse practitioner.

\section{Rationale and Review of Relevant Literature}

Health communication literature details patient dissatisfaction with impersonal health care interactions (e.g. Ben-Sira, 1976; Buller, 1986; Doyle \& Ware, 1977; Fisher \& Todd, 1986). The medical community itself acknowledges that medical education and medical care-giving needs to adhere to a more patient-centred, person-oriented model than to the traditional bio-medical model of Western medicine (e.g. Federman, 1990; Korsch, Gozzi \& Negrete, 1968; Kallen \& Stephenson, 1981; Sox, Morgan, Neufeld, Sheldon \& Tonesk, 1984). Despite this consensually held belief that medical care must incorporate the various relational needs of caregiver and patient (e.g. Burgoon, Pfau, Parrott, Birk, Coker \& Burgoon, 1987; Street \& Wiemann, 1988), medical caregivers and recipients face obstacles as they engage in the medical encounter such as limited time, need for efficient and accurate diagnosis and treatment, and prior beliefs about their 'roles' as 'doctor' and 'patient'. Specifically, if medical interactants attempt to address both medical tasks and patient concerns and comfort (and, hence, expand their relational communication to include talk as 'doctor-patient' with other, more personal relational talk), how do they do so without extending the medical encounter with time-consuming 'personal' time at the end? This question remains unanswered and constitutes a significant gap in health communication research.

The analysis of caregiver-patient interactions detailed in this report attempts to investigate the macro problem of combining medical and interpersonal dimensions of health care from a micro perspective - the analysis of naturally occurring interaction between caregiver and patient. The gynaecologic exam serves as the locus for this analysis because the integration of both person-oriented and medical dimensions is uniquely important to the medical success of the examination and uniquely problematic to its accomplishment, in comparison to other types of medical examinations (e.g. Emerson, 1970; Fisher \& Todd, 1986; Ragan \& Pagono, 1989; Ragan, 1990). Because this study attempted to discern the mutual 
accomplishment of person-oriented and medical activities in the exam, the conversation analytic method was utilised in order to display how patient and medical practitioner oriented to both the interpersonal and the technical-medical aspects of the exam situation. As the following section details, the present research was guided by Bateson's (1951) and Goffman's (1974) concepts of conversational framing and by Gumperz' (1971) sociolinguistic notion of dialect code-switching.

\section{Conversational Framing and Code-Switching}

Bateson $(1951,1956)$ first developed the concept of framing in his theory of play; according to Bateson, who derived this theory from observations of playful zoo monkeys, participants (both animal and human) signal to each other the sort of psychological activity in which they are currenty engaged. Such a psychological 'frame' characterises activity such that interactants realise whether they are in, say, a play frame or a serious frame. Goffman (1974) further elaborates Bateson's theory of framing by noting that strips of serious human activity can be transformed into play through metacommunicative cues or 'keys' that somehow signal interactants that serious, real action has now changed to playful action. The activity both intriguing and perplexing to communication scholars has been the unveiling of the 'somehow'. How exactly is the metacommunicative key accomplished? How do participants cue each other as to what sort of frame they are in? How is intersubjectivity about that frame negotiated and assessed in conversation?

Several researchers investigating the achievement of play in conversation have attempted to pinpoint the ambiguous, metacommunicative 'keys' that Goffman claims to signal frame switches (Adelman, 1989; Glenn \& Knapp, 1987; Hopper, 1987, 1990; Hopper \& Glenn, 1990; Ragan, 1989). In particular, exaggeration (both verbal and non-verbal), verbal repetition, brief time-outs or asides from the mainstream conversation, and speech errors have been shown to key participants to the onset of playful activity in conversation.

The present study attempted to locate those 'keys' that cue participants to the frame that characterises their interaction. Whereas previous researchers have attempted to discover the keys that cue playful activity this research focused on the keys that signal and differentiate medical 'activity' from relational 'activity' in a physical exam. In other words, how are medical and interpersonal frames initiated, negotiated, and terminated in the health care context of the gynaecologic exam?

Along with Bateson's and Goffman's notion that communicators use metacommunicative keys for interpretive purposes, sociolinguistic theory suggests that competent cultural members possess the ability to both recognise situations and to discern their role in those situations relative to others present (e.g. Ervin-Tripp, 1971; Grimshaw, 1971; Gumperz, 1971). Gumperz notes further that communicative competence involves speaking in the 'code' appropriate to one's role in the conversation. According to Gumperz (1971: 101-2), '. . . each role has as its linguistic diacritic a particular code or subcode which serves as the norm for role behavior'. Thus, two individuals may speak differently to each other, contingent on their relative status and position in a given context. Within one encounter, 
however, interactants may shift from one situational definition to another. In a medical exam, for example, the medical practitioner may tell a joke in order to relax the patient for a potentially unpleasant or painful portion of a physical exam or procedure. According to Goffman $(1974,1981)$, such a frame-shift (from medical technician to playful interactant and, presumably, back to medical technician); must include metacommunicative signals which enable the other interactant to identify the 'frame' proposed and to appropriately re-align himself/herself to the new role definitions and the appropriate speech behaviours which fit that frame. Ervin-Tripp (1971: 19) further notes that participants' abilities to shift frames may be particularly difficult in settings 'where status is clearly specified, speech style is rigidly prescribed, and the form of address of each person is derived from his [sic] social identity'. Goffman (1981: 125) contends that the traditions of a particular work place also govern speech behaviour and frame shifting:

In our society, whenever two acquainted individuals meet for business, professional, or service dealings, a period of 'small talk' may initiate and terminate the transaction ... During the business proper of the encounter, the two interactants will presumably be in a more segmental relation, ordered by work requirements, functionally specific authority, and the like.

In a health care encounter, then, practitioners may shift from the code inherent to their defined occupational identity - a code likely to include formal speech use of medical terminology and a focus on medical topics - (Fisher \& Todd, 1986) to a code more oriented to the patient - including person-oriented topics, interpersonal asides, laughter and joking, and so forth (West, 1984). If the health care provider does switch from the institutionally prescribed medical frame to this more interpersonal, patient-oriented relational frame, he/she, according to Goffman's (1974) theories, must key or mark this shift to a different conversational frame, or the attempted shift will be confusing and potentially misunderstood. In short, if the health caregiver does attempt to switch from a strict medical frame to a person-oriented one, s/he must, first, mark that frame shift effectively and efficiently to the health care recipient and, second, use that frame shift to facilitate the holistic treatment of the patient. Because the co-accomplishment of medical and person-oriented activities by health care providers and recipients constitutes a conversational problem for the interactants, the present investigation pursues how such shifts are initiated and oriented to in the context of the gynaecologic exam. The following section details the data base and method of analysis used in the present study.

\section{Data Gathering and Analysis}

Female students, faculty and staff at a large, southwestern university were utilised in this study, based on their requests for contraception and/or annual gynaecologic exams at the campus health centre. The university health centre employs a female nurse practitioner (NP) who is licensed by the state to perform the majority of routine gynaecologic examinations and to do contraceptive counselling. 
All women patients were asked to read a release form which explained the research project and to verbally signal their consent to participate in the study; i.e. to allow their interactions with the LNP to be audio-taped. The university's Institutional Review Board required that verbal rather than written consent be obtained in order to protect the patients' anonymity. A total of 56 women (93\% of the 60 women requesting contraception and/or gynaecologic exams), ranging in age from 18 to 33 , agreed to participate in the study over a three month period. Due to a mechanical error in recording, only 41 of the 56 interactions were recorded in their entirety. The data for this study thus consist of these 41 tape recorded interactions.

Audio-taped recordings were made of these interactions with the aid of a microphone that was suspended from the ceiling over the exam table. The recorded conversations were transcribed so that interactants' talk could be analysed, using the conversation analytic tradition of Sacks, Schegloff, Jefferson, Pomerantz, Frankel, West and others. Transcripts noted in the following section utilise Gail Jefferson's transcribing conventions (Atkinson \& Heritage, 1984).

\section{The 'Doing' of Empathic and Efficient Health Care}

Attention to patients' emotional concerns, in addition to physical symptoms, is not necessarily accomplished by extending doctor-patient interactions. As the present study of a gynaecologic nurse practitioner's interaction with her patients illustrates, first, conversational cues may be used to 'key' brief person-oriented relational asides or timeouts from medical activity. Second, these brief asides serve identification and politeness functions in the conversation which, third, facilitate the on-going relational (i.e. person-oriented or medical) negotiation process between the interactants. In short, brief conversational asides during the medical encounter may enable the medical practitioner to empathically yet efficiently deal with the patient in an approach both holistic and patient-centred.

\section{Keying Devices}

As noted, interactants who attempt to shift from one frame to another during a given conversation must either mark the upcoming shift or likely risk confusing their conversational partners (e.g. 'how should I take this? or 'where did that remark come from?'). In this study, both the nurse practitioner and her patients used such 'keying devices' or 'code shift cues' as verbal hesitations and disfluencies, laughter, transitional words, references to physical objects, and/or a combination of these cues, to mark brief asides or temporary shifts from the medical frame. As the following instance indicates, these keying devices enable the nurse practitioner and her patient to integrate talk about the patient beyond her physical condition. In Excerpt Two, then nurse practitioner examines the patient's breasts and takes her blood pressure while simultaneously shifting talk from medical to person-oriented to medical frames. 


\section{Excerpt Two}

64 NP: Um:m (.) best time though >like I said $<$ is check one $=$ $=$ week after your period $>$ cuz right before $<$ your $=$

70 P: $\mathrm{Mm} \mathrm{hmm}$

71 NP: (Blood pressure pump sound (.4) o:h (hhh) I bet you're= $72=($.) just $>$ can't wait $<$

73 P: I can't wait

74 NP: Ya already have a job there^ or

75 P: $\mathrm{Mm} \mathrm{hmm}$

76 NP: So you're all set (.) just kinda (.) >pick in up=

77 =yourself an goin $<$ huh` (.) that's neat $($.$) ya like =$

$78=$ to $\mathrm{ski}^{\wedge}$

79 P: oh yah

80 NP: if ya like to ski (.) that's the best place for ya huh^=

$81=$ hhh

82 P: $\mathrm{mm} \mathrm{hmm}$

83 NP: (water running sound on and then off) (.2) okay (.) your=

84 P: knees can $>$ kinda fall $<$ to tha side like $>$ sittin Indian $=$

$85=$ style (.2) now I'm gonna check the outside first

In Lines 64-67, NP tells the patient the best time to examine her breasts and concludes these instructions in Line 68 with 'okay' ${ }^{\wedge}$ and a brief pause (.). Receiving no verbal response, NP continues in Line 68 and adds further closure on that segment of conversation with 'there ya go', another slightly longer pause, an 'okay', and another pause (.). In Lines 68-69, NP initiates a new, non-medically related topic, the patient's move to Denver. NP receives a brief affirmation from the patient in Line 70; however, NP pauses in Line 71 as she takes P's blood pressure. After the sound of the blood pressure pump subsides in Line 71, NP immediately returns to the person-oriented aside from the medical frame, marked by the extended ' $\mathrm{o}: \mathrm{h}$ ' and a breath intake. NP and P discuss the move to Denver in Lines 72-82; however, NP keys a shift back to the medical frame in Line 83 by running the water (perhaps warming the speculum), pausing, using 'okay' as a transition word, and again pausing briefly. She then tells $P$ what position to assume and what procedure to expect. These frame shift cues enable both interactants to make sense of the talk and to respond with appropriate behaviour.

Despite the concern by doctors that adding person-oriented talk to necessary medical tasks unnecessarily extends the medical interview by adding talk at the end of the interview or by getting the encounter 'off track', Excerpts One and Two (and numerous other examples in the transcripts analysed) indicate that brief asides (which enable the medical interactants to address the patient as a person with related, non-medical needs) may be marked as such and that the medical 
practitioner may then return to medical business. The following section details the function of these asides within gynaecologic interactions.

\section{Functions of Asides}

As this study exemplifies, the significance of these conversational asides to the on-going negotiation between the nurse practitioner and patients extend beyond their ability to recognise and acknowledge these frame shifts in conversation. More importantly, these asides function rhetorically as identification and politeness strategies within the conversation.

\section{Asides as identification strategies}

Although many medical practitioners continue to argue that patient compliance must be gained by stressing and perpetuating the institutional differences between doctors and patients (e.g. DiMatteo \& DiNichola, 1982), Burke (1950) and his proponents contend that communicators must transcend differences (on at least some level) in order to communicate effectively and persuasively. Further, Burke (1950: 46) argues that identification, the establishing of a common ground of ideas, is central to any persuasive attempt:

As for the relation between 'identification' and 'persuasion': we might well keep it in mind that a speaker persuades an audience by the use of stylistic identifications; his act of persuasion may be for the purpose of causing the audience to identify itself with the speaker's interests; and the speaker draws on identification of interests to establish rapport between himself and his audience. So, there is no chance of our keeping apart the meanings of persuasion, identification ('consubstantiality') and communication (the nature of rhetoric as 'addressed').

In her interactions with patients, this nurse practitioner recurrently integrates asides which serve as a type of identification strategy. As Excerpt Three indicates, through these asides, the nurse practitioner stresses her commonality with the patients on some level and then effectively reasserts (via keying devices) her institutional authority to direct the encounter. In short, through these identification strategies, the nurse practitioner gains a short term rapport with the patient which may facilitate patient compliance with the medical examination and prescribed future behaviour (e.g. breast self-examination, proper pill use, etc.).

\section{Excerpt three}

47 NP: Oh okay hhh (.) or if ya miss it like (.) a couple days $=$ $48=$ in a month $<($.) then $()>$. ya know< $($.$) that increases =$ $49=$ your chances of ovulation especially if you're $>$ right $=$ $50=$ in tha middle ov $<$ your packets $(\mathrm{hhh}) \mathrm{uh}: \mathrm{h}$ but if ya= $51=$ take em exactly like you're supposed to (.) then you= $52=$ shouldn't get pregnant unless you're $($.$) like (.) >$ one $=$ 
$53=$ in a million $<$ women $\mathrm{h}[\mathrm{hh}$ that $]=$

54 P: $\quad$ [hhh >that'll] be mer

55 NP: for hhh some reason >probly would've been $<$ me too $()=$.

$56=$ um:m $(.2)$ what I'd dos $($.$) is is ()>$. when is $<$ your next $=$

$57=$ period $>$ spose to come ${ }^{\wedge}\left(\right.$ (.) $>$ pretty soon ${ }^{\wedge}$

After explaining the increased chance of pregnancy due to inappropriate use of the pill in Lines 47-51, NP stresses that, with correct pill-taking procedures, $\mathrm{P}$ 'shouldn't get pregnant unless' she's like '>one in a million''; however, NP perhaps attempts to emphasise this minimal risk by briefly laughing at the end of Line 53 . $P$ joins in this laughter in Line 54 and comments that 'that'll be me'. Instead of simply reasserting the medical improbability of such an unexpected pregnancy, NP attempts to identify with P's concern by adding that 'for hhh some reason >probly would've been ' me too' in Line 55. In short, NP does not discount the concern, however jokingly advanced, but she instead recognises it not only as a real concern for P but also for herself. After this brief aside which identifies NP with P, NP uses a transition vocalisation (um:m) and a pause to shift back to the medical frame where she questions $\mathrm{P}$ about the date of her next period in Line 56.

Excerpt Four also exemplifies NPs' recurrent asides which display her understanding of P's concerns. In Excerpt Four, NP attempts to dispell P's concern about the risks of taking the pill by drawing an analogy between the risks of the pill and the risks of caffeine. In so doing, NP identifies with P in that coffee's 'bad for you anyway' (Line 18) but 'we all drink it' (Lines 18-19).

\section{Excerpt Four}

17 NP: If there's no history (.) > ya shouldn' , worry but $()=$.

18 = ya know < coffee's bad for you anyway $($.$) hhh but we=$

19 =all drink it $[\mathrm{hhh}]=$

20 P: $\quad[$ hhh]

21 NP: $=($.$) okay (.) kindov let your knees fall to the side$

In response to P's concern that the pill may cause cancer, NP probes and learns that P's family has no history of ovarian cancer. She then attempts to defuse P's concern in Line 17 by telling her that 'ya shouldn't worry' and then by drawing the analogy with coffee in that 'coffee's bad for you anyway (.) hhh but we all drink it' in Lines 18-19. NP then initiates a laugh which $P$ promptly joins in Line 20. NP does not undermine P's concern raised about subsequent health risks because of the pill by citing medical statistics or by guaranteeing her of the pill's safety. Instead, she tells her not to worry and draws a parallel with another substance that 'we all' use even though it has potential risks.

Through these person-oriented asides, the nurse practitioner establishes that she knows and understands the patient's concerns, and hence, can identify with such concerns. From that rhetorical foundation, the nurse practitioner is in an excellent position not only to potentially dispell those concerns but also to gain patient compliance for taking medication as prescribed or for doing breast selfexaminations. This position is further enhanced by the nurse practitioner's use of asides as politeness strategies, as the next subsection details. 


\section{Asides as politeness strategies}

Although the patients in the current study did allow the nurse practitioner to direct the conversation by recurrently shifting frames, these encounters were atypical of traditional medical interviews (e.g. Fisher \& Todd, 1986; West, 1984) in that the nurse practitioner took frequent 'time-outs' from the regular medical encounter to engage in a politeness strategy. In so doing, she enables patients to assert an opinion or to react to a medical procedure without causing them embarrassment or 'loss of face'. Goffman (1955: 215-16) found that such concern for others' 'face' or self esteem seems to be inherent to interaction:

Just as the member of any group is expected to have self-respect, so also he is expected to sustain a standard of considerateness . . . This kind of mutual acceptance seems to be a basic structural feature of interaction, especially the interaction of face-to-face talk.

This concern for face saving or politeness is particularly important and problematic in medical interactions, where one interactant holds institutional authority and typically superior knowledge. If medical practitioners answer patient questions or comments while inferring that the questions were 'silly' or 'unfounded', then patients will not likely risk again losing face (and, hence, will possibly fail to raise crucial questions or concerns). The medical practitioner then faces the challenge of responding tactfully (i.e. providing the patient with a facesaving device if a question or concern is unfounded) while correcting any misinformation or misinterpretation. Brown \& Levinson (1987: 68) explain that interactants weigh the potential cost of using a potential face threat (i.e. correcting the patient's incorrect information) with the potential cost of not telling the patient that his/her information was inaccurate. Brown \& Levinson (1987: 68) argue that if the potential risk to ' $B$ ' would be more harmful than potentially 'losing face', then ' $A$ ' will likely risk the face threat to ' $B$ ' by telling ' $B$ about the threat (i.e. the misinformation of error). However, if the potential risk to ' $B$ ' is less than that of the potential face threat, 'A' will likely spare 'B's' face. Throughout this decision, the interactant maintains the desire to save his/her partner's face to the highest possible degree.

In Excerpt Five, the nurse practitioner responds to her patient's misinformation about the frequency for the Pap smear test (and the resultant, subtle challenge to NP's authority) by recurrently shifting from the medical frame to conversational asides used as politeness strategies to the medical frame and vice versa.

\section{Excerpt Five}

1 NP: Did you have a pap smear ${ }^{\wedge}$ (.) (Paper rustling)

2 P: Yah

3 (.)

4 NP: Okay (.2) (Paper rustling) when waz that at ${ }^{\wedge}($.$) was =$

$5=$ it done here

6 P: Yah

$7 \quad$ (.2) (Paper rustling) 
8 NP: Mm kay well >you really don't $<$ need another pap smear now

$9 \quad($.

10 P: Aren't $>$ cha sposed ta $<$ have um >evry six months $<$

11 (.)

12 NP: No:o (.) once a year=

13 P: Oh that's what $>$ somebody told me $<=$

14 NP: Oh no >once a [year<]

15 P: [>it's why ] I come in cuz I don want=

$16 \mathrm{NP}:$ = well let me see [what] $=$

17 P: $\quad$ [indistinguishable]

18 NP: = your last hhh hhh $>$ ya don wanta take $<$ any chances huh ${ }^{\wedge}=$

$19=[\mathrm{hhh}]$

20 P: [hhh]

$21 \quad$ (.)

22 NP: let me see what your last pap smear showed okay^ (.) if $=$

23 Eyou had it in December (.) you won't need another $\bar{p}$ ap $=$

$24=$ smear

25 P: okay

$26 \quad$ (.)

27 NP: Um:m (.) tha pap smear waz fine

28 P: okay

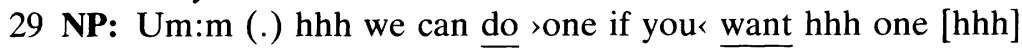

30 P:

$31=>$ that's okay $<$ hhh

32 NP: Uh:h (.) >you'll pass $<$ hhh huh^ (.) um (.) no (.) what we =

33 P: =can do is (.) uh $>$ you know $<$ you might just $($.$) your body =$

$34=>$ trying to readjust to these pills $<(\mathrm{hhh})$ now one thing $=$

After the patient voices a concern about infrequent periods, the nurse practitioner asks, in Line 1, whether $\mathrm{P}$ had had a pap smear at her last check up. $P$ responds affirmatively in Line 2, and after a brief hestitation (Line 3), NP says 'okay' and continues to look for details of the pap smear (evidenced by the continued sound of shuffling paper and additional questions in Lines 4-7). As the sound of paper rustling ends, NP asserts that P 'really' doesn't 'need another paper smear now' in Line 8. After another brief hesitation (Line 9), P questions NP's conclusion about the necessity of a pap smear at this time (Line 10). NP hesitates in Line 11 and then responds that 'no', $\mathrm{P}$ only needs a pap smear 'once a year'. NP's response in Line 11, however, is offered cautiously rather than decisively, given the extended 'no:o' followed by a hesitation. Although P's initial concern about NP's advice (Line 8) was posed as a question in Line 10, P again voices her concern in Line 13 by citing an unnamed source as 'someone who told' her about the frequency of the pap smear. Given that NP's initial attempt to ease P's concern about her conclusion had been followed by a stronger challenge, NP reasserts her position, in Line 14, by stressing the 'no' and repeating that the pap smears are only due 'once a year'. In her third challenge to NP's conclusion in Line 15, P emphasises that the 'need' for a pap smear is why she came to the 
nurse practitioner and, although she is cut off by the nurse practitioner in Line 16, her 'I don't want' potentially indicates that she fears for her health.

Given P's continued assertions, NP again refers to P's medical chart to confirm her opinion of P's situation (i.e. what the results of her 'last' pap smear showed) in Line 16. However, NP interrupts the medical business to integrate a brief aside which serves as a politeness strategy in Line 18 after three unsuccessful (yet potentially face threatening) assertions that $P$ lacks accurate information (Lines 8, 12 and 14). She first laughs and then provides $P$ with a rationale for her persistence by asking 'ya don wanta take any chances huh`', followed by laughter shared by both NP and P. After a brief pause (Line 21), NP shifts back into the medical frame in Lines 22-24 by referring to the chart and by reasserting that if you had it in December (.) you won't need another pap smear'. P accepts this statement as fact in Line 25 by saying 'okay'.

After another quick pause in Line 26, NP emphasises that the 'pap smear was fine', and $P$ again simply says 'okay' in Line 28 . However, instead of progressing with the medical encounter, NP asserts another aside in Line 29 by using a transition word, a pause and brief laughter before stressing that 'we can do >one if you< want hhh one [hhh]'. NP makes this offer while also integrating segments of laughter, thus offering the patient two 'outs'. If $\mathrm{P}$ is still truly concerned, she now has an opportunity to request a pap smear without again losing face. Further, NP invites $P$ to join her in shared laughter about the idea of a pap smear rather than dwelling on her concern or misinformation about the pap smear. These two 'outs' provide $\mathrm{P}$ with a way to save face during a potentially face threating situation.

As shown in Excerpt Six, the nurse practitioner also uses brief relational asides to acknowledge patient nervousness or discomfort and to dispell potential patient embarrassment. In Excerpt Six, the nurse practitioner is actually performing the pelvic examination when she initiates the brief relational aside which serves as a politeness strategy.

\section{Excerpt Six}

90 NP: now $>I$ 'm going ta relax $<$ your vaginal muscle with my=

$91=$ finger (.) okay^ $(.2)$ an this iz tha speculum $(.3)=$

$92=$ a little tender ${ }^{\wedge}($.$) okay there ya go ($.$) okay ()=$.

$93=$ think about relaxing that (.) >a little bit $=$

$94=$ uncomfortable $<$ isn't it ${ }^{\wedge}$

95 (.)

96 P: Yah

97 NP: I'll try to be as >quick as I can<

In Lines 90-91, NP tells P about the procedure that she is about to use, pauses and checks to see if $P$ is 'okay' (either with her explanation of the procedure or her physical state). After a pause, NP introduces the speculum and again pauses. However, NP attends, in Line 92, to P's apparent nonverbal behaviour (i.e. movement, wince, etc.) by asking, 'a little tender' ${ }^{\wedge}$. NP hesitates, uses a transition word, 'okay', and again hesitates before giving the instruction to $\mathrm{P}$ in Line 93 to 'think about relaxing that'. However, after another hesitation in Line 93, 
NP again responds to P's nonverbal behaviour by asking/acknowledging that it's ', a little bit uncomfortables' with her tag question, 'isn't it' After P hesitates (Line 95 ) and then responds verbally in Line 96 that 'yah' the procedure is uncomfortable, NP assures P that she'll 'be as quick as I can'.

Throughout the interaction in Excerpt Six, NP both acknowledges P's discomfort and offers $\mathbf{P}$ candidate excuses for making that discomfort apparent to NP (i.e. 'it's a little uncomfortable' and it's 'a little tender'). Hence, NP's integration of both medical and person-oriented frames likely facilitates the actual physical examination in addition to building patient satisfaction and compliance.

By integrating these recurrent asides which function as identification and politeness strategies, this nurse practitioner succeeds in dealing with the patient holistically, rather than viewing the patient only in terms of her physical symptoms. Further, this holistic treatment is accomplished throughout the encounter by recurrently, briefly diverting to a nonmedical frame. Given the frequent frame shifts in the interactions between the nurse practitioner and her patients in these gynaecologic interactions, the following concluding remarks suggest that these interactions consist more of an on-going negotiation process than a routine, traditional medical interview.

\section{Conclusion}

This conversation analysis of a nurse practitioner and her patients' interactions preceding, during and following a gynaecologic examination indicates, first, that the interaction is an on-going accomplishment which the participants jointly negotiate and coordinate; second, that the use of subtle code shift cues facilitate the shifting between medical and person-oriented frames, and third, that these brief relational asides potentially serve a function beyond mere pleasantries to the interactants. This section will summarise these findings and offer potential hypotheses for future research.

Despite Fisher \& Todd's (1986: 6) argument that '. . . the interactants - medical practitioners and patients - are not equal partners in the decision-making process', the nurse practitioner and her patients work together to accomplish not only the interaction but also the medical examination in and of itself. By responding to unspoken patient 'needs' during the examination (e.g. discomfort) and attempting to dispell patient embarrassment resulting from indicating that discomfort, the nurse practitioner may facilitate the medical examination and subsequent patient satisfaction with the encounter. However, this claim remains an empirical question which needs to be tested. Further, by indicating such discomfort and recognising and affirming the nurse practitioner's frame shift cues, the patient also actively works with the nurse practitioner to complete the examination. However, again, the claim that such active participation leads to positive health outcomes is a second empirical question to be addressed in future research.

Second, as the previous excerpts exemplify, these interactional partners initiate and recognise the frame shift cues to move expediently from the medical frame to the various relational asides. During the present study, neither interactant offered 
nor requested clarification as to 'where that statement came from?' or 'what are you talking about?' Further, these frame shifts were affirmed by the non-initiating interactant (typically the patient) through laughter or words indicating affirmation or alignment. A third claim which requires further testing, however, is that the frame shifts accomplished are recognised by the participants as 'medical' or 'person-oriented'.

Finally, whereas previous researchers discovered ways in which frames may be shifted (i.e. from serious to play), the present study extends that research by noting possible functions that these frame shifts may serve in conversation. The present conversation analysis indicates that these relational asides may, indeed, facilitate the medical examination and subsequent patient satisfaction without increasing the length of the examination. This claim constitutes a fourth potential hypothesis for future research. Specifically, do these asides increase patient satisfaction; do they function, for the interactants, as indicated by their talk, and do all 'relational' asides accomplish the same outcome in the medical encounter?

Although doctors often complain that they can't take the time to integrate the relational dimension into the medical encounter, the nurse practitioner in the present study effectively and efficiently moved from medical to relational to medical frames while simultaneously performing medical procedures (e.g. taking blood pressure, making notes on the chart, conducting breast or pelvic exams and instructing the patient about proper pill usage). Further, the nurse practitioner's ability to quickly shift from the medical frame to a person-oriented aside enabled her to use an identification or politeness strategy at the point in the examination that it was needed. Hence, the nurse practitioner's ability to use relational asides as identification or politeness strategies facilitated the patient's cooperation with nurse practitioner directives such as 'you need to relax' or 'you need to take the pill this way'.

While the present study focused on the gynaecologic exam, future research should investigate, in addition to the potential hypotheses noted previously, other medical examination settings as well as other medical practitionerpatient interactions such as male doctors and female patients. One question that remains unanswered in the present study is whether the nurse practitioner was able to identify with 'the girls' because she was a woman close to her patients' ages.

Regardless of the variations in medical settings and between medical interactants of differing ages and sexes, however, the present study suggests how these shifts are achieved within the conversation and the potential functions that these asides may serve.

\section{References}

Adelman, M. (1989) Sustaining passion: Eroticism and safe-sex talk. Paper presented at the Annual Meeting of the Speech Communication Association, New Orleans, LA.

Atkinson, J. M. and Heritage, J. (ed.) (1984) Structures of Social Action: Studies in Conversation Analysis. Cambridge: Cambridge University Press. 
Bateson, G. (1951) Steps to an Ecology of Mind. San Francisco: Chandler.

- (1956) The message 'this is play'. In B. Schaffner (ed.) Transactions of the Second Conference on Group Processes. New York: Josiah Macy, Jr. Foundation.

Ben-Sira, Z. (1976) The function of the professional's affective behavior in client satisfaction: A revised approach to social interaction theory. Journal of Health and Social Behavior 17, 3-11.

Brown, P. and Levinson, S. C. (1987) Politeness: Some Universals in Language Use. Cambridge: Cambridge University Press.

Buller, M. K. (1986). Physician communication style and patient satisfaction. Paper presented at the Annual Meeting of the International Communication Association, Chicago, IL.

Burgoon, J. K., Pfau, M., Parrott, R., Birk, T., Coker, R. and Burgoon, M. (1987) Relational communication, satisfaction, compliance-gaining strategies, and compliance in communication between physicians and patients. Communication Monographs 54, 30724.

Burke, K. (1950) A Rhetoric of Motives. New York: Prentice-Hall.

DiMatteo, M. R. and DiNicola, D. D. (1982) Achieving Patient Compliance: The Psychology of the Medical Practitioner's Role. New York: Pergamon.

Doyle, B. J. and Ware, J. E. (1977) Physician conduct and other factors that affect consumer satisfaction with medical care. Journal of Medical Education 52, 793-801.

Emerson, J. (1970) Behavior in private places: Sustaining definitions of reality in gynaecological examinations. In H. P. Dreitzel (ed.) Recent Sociology, No. 2: Patterns of Communicative Behavior. New York: MacMillan.

Ervin-Tripp, S. M. (1971) Sociolinguistics. In J. A. Fishman (ed.) Advances in the Sociology of Language. The Hague: Mouten.

Federman, D. D. (1990) The education of medical students: Sounds, alarms, and excursions. Academic Medicine 65, 221-6.

Fisher, S. and Todd, A. D. (eds) (1986) Discourse and Institutional Authority: Medicine, Education, and the Law. Norwood, NJ: Ablex.

Friedson, E. (1961) Patients' Views of Medical Practice. New York: Russell Sage.

Glenn, P. J. and Knapp, M. L. (1987) The interactive framing of play in adult conversations. Communication Quarterly 35, 48-66.

Goffman, E. (1974) Frame Analysis. New York: Harper \& Row.

- (1981) Forms of Talk. Philadelphia: University of Pennsylvania Press.

Grimshaw, A. D. (1971) Sociolinguistics. In J. A. Fishman (ed.) Advances in the Sociology of Languages. The Hague: Mouton.

Gumperz, J. (1971) Language in Social Groups: Essays by John J. Gumperz. Stanford: Stanford University Press.

Hopper, R. (1990) Speech errors and the poetics of conversation. Paper presented at the Annual Meeting of the Speech Communication Association, Chicago, IL.

- (1987) Beginning to play: Reflections on Bateson's 'theory of play and fantasy'. Paper presented at the Annual Meeting of the Western Speech Communication Association, Salt Lake City, UT.

Hopper, R. and Glenn, P. (1990) Repetition and play in conversation. Paper presented at the Annual Meeting of the Speech Communication Association, Chicago, IL.

Kallen, D. J. and Stephenson, J. J. (1981) Perceived physician humaneness, patient attitude and satisfaction with the pill as a contraceptive. Journal of Health and Social Behavior 22, 256-67.

Korsch, B. M., Gozzi, E. K. and Negrete, V. F. (1968) Gaps in doctor-patient interaction and patient satisfaction. Pediatrics 42, 855-70.

Ragan, S. L. (1990) Verbal play and multiple goals in the gynaecological exam interaction. Journal of Language and Social Psychology 9, 61-78.

- (1989) When it is not a laughing matter: Unshared laughter in gynecologic health care interactions. Paper presented at the Ninth Annual Temple University Discourse Analysis Conference, Philadelphia, PA. 
Ragan, S. L. and Pagano, M. (1987) Communicating with female patients: Affective interaction during contraceptive counselling and gynecologic exams. Women's Studies in Communication 10, 45-57.

Sox, H. C., Morgan, W. L., Neufeld, V. R., Sheldon, G. F. and Tonesk, X. (1984) Subgroup report on clinical skills: Physicians for the 21st century. Journal of Medical Education 59, 139-47.

Street, R. L. and Wiemann, J. M. (1988). Differences in how physicians and patients perceive physicians' relational communication. Southern Speech Communication Journal $53,420-40$.

West, C. (1984) Routine Complications: Troubles with Talk between Doctors and Patients. Bloomington, IN: Indiana University Press.

\section{Mediating Languages and Cultures Edited by Dieter Buttjes and Michael Byram}

The history of "language teaching" is shot through with methods and approaches to language learning - most recently with "communicative language teaching" - but this book demonstrates that a more differentiated and richer understanding of learning a foreign language is both necessary and desirable. Languages and cultures are interlinked and interdipendent and language and culture teaching and learning should be too. Learning another language is part of a complex process of learning and understanding other people's ways of life, ways of thinking and socio-cultural experience.

This book brings together contributions on this theme from variety of disciplines from a number of countries. It offers for the first time a framework for the development of coherent theory and practice for intercultural learning in the context of language teaching.

Hbk ISBN 1-85359-071-1 $£ 48.00$ (US\$99.00)

Pbk ISBN 1-85359-070-3 $£ 17.95$ (US\$39.00)

MM60 352 pages

1990

MULTILINGUAL MATTERS LTD

Bank House, 8a Hill Road,

Clevedon, Avon, England, BS21 7HH

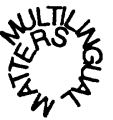

